EVIDENCE BASED PUBLIC HEALTH POLICY AND PRACTICE

\title{
Injecting drug use in Brighton, Liverpool, and London: best estimates of prevalence and coverage of public health indicators
}

\author{
Matthew Hickman, Vanessa Higgins, Vivian Hope, Mark Bellis, Kate Tilling, Angeline Walker, \\ John Henry
}

J Epidemiol Community Health 2004;58:766-771. doi: 10.1136/jech.2003.015164

See end of article for authors' affiliations

Correspondence to: Dr M Hickman, CRDHB Social Science and Medicine, Imperial College, Charing Cross Campus, St Dunstans Road, London SW6 1RQ UK; m.hickman@imperial. ac.uk

Accepted for publication 28 October 2003

\begin{abstract}
Study objective: To estimate the prevalence of injecting drug use (IDU) in three cities in England and to measure the coverage of key public health indicators.

Design: Capture-recapture techniques with covariate effects.

Setting: Liverpool, Brighton, and 12 London boroughs, 2000/01.

Participants: IDU collated and matched across five data sources-community recruited survey, specialist drug treatment, arrest referral, syringe exchange, and accident and emergency-896 in Brighton, 1224 in Liverpool, and 6111 in London.

Main results: It is estimated that in 2000/01 the number and prevalence of IDU aged 15-44 was 2300 $(95 \% \mathrm{Cl} 1500$ to 3700$)$ and $2.0 \%(95 \% \mathrm{Cl} \% 1.3 \%$ to $3.2 \%)$ in Brighton; $2900(95 \% \mathrm{Cl} 2500$ to 5000$)$ and $1.5 \%(95 \% \mathrm{Cl} 1.3 \%$ to $2.6 \%)$ in Liverpool; $16700(95 \% \mathrm{Cl} 13800$ to 21600$)$ and $1.2 \%(95 \% \mathrm{Cl} 1.0 \%$ to $1.6 \%$ ) in 12 London boroughs; with a prevalence of $1.7 \%(95 \% \mathrm{Cl} 1.2 \%$ to $3.3 \%)$ in inner London. It is estimated that: less than one in four IDU are in treatment in the three areas; syringe exchange programmes covered about $25 \%$ of injections in Brighton and Liverpool and $20 \%$ in London; and that the annual opioid mortality rate among IDU was $2 \%$ in Brighton compared with less than $1 \%$ in Liverpool and London.

Conclusions: Credible estimates of the prevalence of injecting drug use (and key public health indicators) can be determined using covariate capture-recapture techniques. These suggest that: targets to double the number in treatment are possible: syringe distribution should be increased; and further attention, especially in Brighton, given to reducing overdose mortality.
\end{abstract}

prevalence of "addiction" was first recognised by Bishop et al, ${ }^{16}$ and one off estimates have been generated for many cities worldwide. ${ }^{17-23}$

In this study we focus on three cities in England (Brighton, Liverpool, and part of London), using new developments in the analysis of capture-recapture studies to estimate the number of injecting drug users (IDUs)..$^{25}$

\section{METHODS \\ Overview}

In capture-recapture, two, but ideally three, or more data sources that identify the target population (that is, IDUs) are collected and matched using name, or often, as in our case, a set of "attributors" (person initials, date of birth, and sex) to identify the number of individuals in the whole dataset and the number of matches (that is, the number of people that occur in more than one data source). An equivalence is assumed between the level of overlap between the data sources (that is, the proportion of subjects in two or more data sources) and the sampling intensity (that is, the proportion of the total population recorded by the data sources). Simple equations or statistical models fitted to the observed data are used to estimate the number of injecting drug users who appear in none of the data sources, which combined with the observed number generates the prevalence estimate. The data sources and the statistical techniques used are summarised below.

Abbreviations: IDU, injecting drug use; SEP, syringe exchange programme; A\&E, accident and emergency variety of conditions including diabetes, congenital disorders, infectious disease, and injury. ${ }^{12}{ }^{14}{ }^{15}$ Its use for estimating the 
The study was granted ethical approval by the Scottish Multi-Centre Research Ethics Committee, and 12 local research ethics committees.

\section{Data sources}

The target population was injecting drug users aged 15-44 resident in Liverpool city (population 195000 aged 15-44), Brighton and Hove (117 000 aged 15-44), and 12 London boroughs comprising about one third of London and $60 \%$ of inner London (see footnote to table 1, population 1.36 million aged 15-44) during the period April 2000 to end March 2001. Data including matching attributors' drug, and area of residence were collected from five sources:

1. Arrest referral: routine monitoring data were available electronically on assessments by arrest referral workers (who are located in police custody suites throughout England to assess drug problems of arrestees and refer, if appropriate, to a specialist drug agency ${ }^{26}$ ).

2. Drug treatment: electronic data were retrieved from local databases and the National Drug Treatment Monitoring System, which collect reports of new and ongoing clients at specialist drug treatment agencies and a few primary care services.

3. Syringe exchange programmes (SEP): computerised records of two in Liverpool, and manual collection from one in Brighton and 10 in London.

4. Accident and emergency (A\&E): attendees because of an overdose were identified through A\&E computers and data extracted from patient notes from one hospital each in Liverpool and Brighton and 10 in London.

5. Community recruited survey: injecting drug users resident in the study area were interviewed using indigenous fieldworkers recruiting subjects from the street or social networks: 96 in Brighton, 151 in Liverpool, and 436 in London.

The A\&E and community survey data sources in Brighton and Liverpool were combined because they were small, and in London they were combined further with arrest referral in order to cover the geographical area. Criteria for matches (subjects on more than one dataset) were: identical initials, date of birth, and gender; initials reversed, identical date of birth, and gender; number substitution in date of birth, identical initials, and gender. Three public health indicators were collected from a variety of sources (see footnote to table 3): number in specialist drug treatment ${ }^{6}$; annual number of syringes distributed through syringe exchange services ${ }^{27}$; and opioid overdose deaths. ${ }^{28}$

\section{Statistical techniques}

The assumptions underpinning capture-recapture and the estimation equations are described in detail elsewhere. ${ }^{12} 141624$ Two key biases that need to be controlled are "dependency" and "heterogeneity". Dependencies arise if a person in one data source is more or less likely to be on another data source (for example, IDU in specialist drug treatment are more likely to be registered with a local syringe exchange programme than IDU not in treatment), and are simply tested by fitting an interaction between the data sources with the Poisson model and calculating whether this improves the fit of the model. With four data sources there are 114 potential models from "independence" (no interactions) to all three way interactions between the data sources.

Heterogeneity arises if the probability of being captured by a source is not equal for all members of the target population. Most health and criminal justice data will exhibit heterogeneity. ${ }^{12}$ For example, there were proportionally more males and subjects were younger in the arrest referral data source

\section{Policy implications}

- Evidence on the number of injecting drug users can be obtained, but these studies are labour intensive. Introducing "prevalence estimation" as an objective of routine surveillance and condition of government investment is the answer to how the situation can be improved.

- Better quality data are required on the number of people in treatment, to make best use of evidence on the prevalence of injecting drug use.

- Syringe distribution at least in three cities in England may not be adequate to prevent transmission of hepatitis $C$.

- Identifying effective interventions to prevent and/or reverse transitions to injection drug use must become a critical public health action.

compared with the other data sources. The traditional capture-recapture approach has been to stratify the dataset to form homogeneous subsets, and then to carry out capturerecapture estimations separately on each subset. However, this increases the number of models (for each age group and gender, etc) used to provide estimates, involving multiple significance testing, and in small subsets (for example, young women) reducing the statistical power to distinguish the best model. Covariate capture-recapture techniques developed by Tilling et $a^{24}$ adjust for heterogeneity more efficiently within fewer models through expanding the observed dataset to include covariates. Covariates (age group and sex) were both included as categorical values, given no reason to assume that the probability of capture varied linearly with age. In effect, by including all interactions between covariates the estimates will equate to a stratified solution, which also assumes no high order interactions, but it tests whether a different stratified model is justified and so leads to a more parsimonious model.

In this study, covariates (age group and gender) were created and included in the model by generating multiple dummy variables denoting dependencies between data sources and between covariates and the data sources, and Poisson models were fitted to the data sources and covariates and the overlap between them. Covariate analysis followed stratified analysis where within each strata the best fitting model, with the fewest parameters and smallest difference between observed and predicted values, was selected on the basis of standard information criterion. In the stratified analysis these included the likelihood ratio test (LRT) for competing models with different numbers of interactions, and the Bayes information criterion (also known as Drapers information criterion, DIC) or Akaike information criterion $(\mathrm{AIC})^{129}$ (data not shown). We adopted this approach to select the simplest model given a variety of information criterion, though some analyses in the literature recommend the AIC as preferable. ${ }^{30}$ The covariate analysis began with all the interactions identified by the stratified analysis, and then selected the most parsimonious model (that is, with fewest parameters) based on the lowest AIC. The "best fitting poisson model" was used to generate estimates of the unobserved number of male and female IDU aged 15-29 and 30-44..$^{24} 25132$ Ninety five per cent confidence intervals (CI) were generated using bootstrap methods. ${ }^{33}{ }^{34}$ These deal with model uncertainty, but assume that the model is correct, which we preferred to a solution that weights different models. 


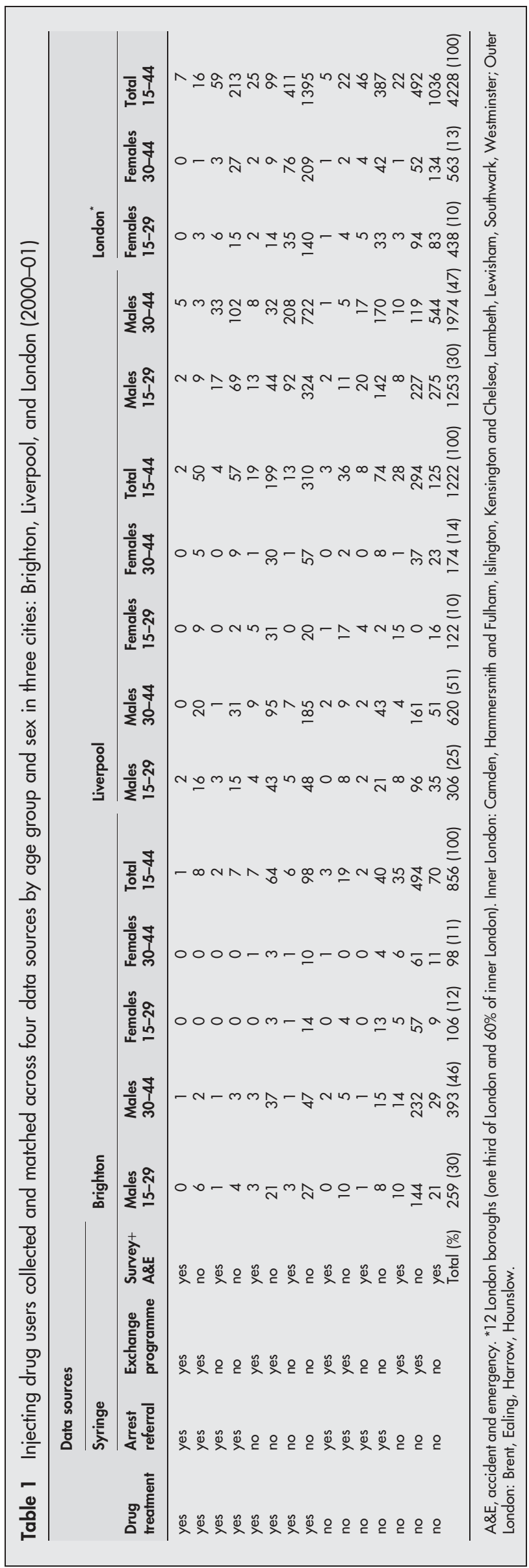

In this study information on ethnic group and sub-city geographical area were not sufficiently complete or reliable from the data sources and could not be included as covariates in the final analysis. In London, data on area of residence were used to classify whether subjects resided within the 12 London boroughs. However, the study did not permit the collection of full postcode to classify subjects reliably to an individual borough, also during the 12 month study period subjects reported different boroughs of residence within and between the data sources. Separate models were run for London boroughs, inner London and outer London (data not shown) but these entailed extensive recoding of subjects to one or other geographical area and could give a range of estimates (depending on whether borough and inner and outer London was defined inclusively or exclusively) that were considered less reliable than the overall model. To estimate the prevalence for inner and outer London the estimate was apportioned according to the observed data, and assuming that the ratio of observed to unobserved subjects were the same.

\section{RESULTS}

Table 1 shows the observed datasets for the three cities, including the number of injecting drug users collected by the data sources and the number of individuals matched between them. Overall, in Brighton 1074 records were collected of 856 individuals, 17\% of whom appeared on more than one data set and one appeared on all four datasets. In Liverpool, 1669 records were collected of 1224 IDU, 31\% appeared on more than one dataset and two individuals were on all four datasets. In London, 5302 records were collected of 4252 individuals of whom $21 \%$ were on more than one dataset and 91 appeared on all three. In the three sites about $24 \%$ of the observed subjects were female, and less than half of the subjects aged $15-29$ (43\% in Brighton, 40\% in London, and $35 \%$ in Liverpool). In London about 13\% of the observed data were residents of the four outer London boroughs.

Table 2 shows the estimates of the unobserved population and prevalence (based on the best fitting model shown in the footnotes). In Brighton, an additional 1448 injecting drug users not observed by the study data sources were estimated giving a total of about 2300 injectors (95\% CI 1500 to 3700), which in a population of just over 100000 aged 15 to 44 gives a prevalence of $2.0 \%$ (95\% CI $1.3 \%$ to $3.2 \%$ ). In Liverpool, an additional 1688 unobserved injectors were estimated giving a total of about 2,900 (95\% CI 2500 to 5000) injectors and a prevalence of $1.5 \%$ (95\% CII.3\% to $2.6 \%$ ). In the 12 London boroughs, an additional 12547 injectors were estimated giving a total of over 16700 (95\% CI 13800 to 21 600) and a prevalence of $1.2 \%$ (95\% CI $1.0 \%$ to $1.6 \%$ ).

The London estimate, when divided into inner and outer London, suggest that that the prevalence in outer London was less than a third of that in inner London $(0.4 \%, 95 \%$ CI 0.3 to $0.8 \%$, and $1.7 \%$, 95\% CI $1.2 \%$ to $3.3 \%$ respectively). These figures imply also that in London, as a whole, there was $34400(1.0 \%)$ injectors aged 15 to 44, with 25000 in inner London. The ratio of unobserved to observed (that is, how many unobserved injectors there were for each observed injector in the dataset) was less than two for Brighton and Liverpool, and about three for London.

The estimated prevalence varied by age and gender in all three areas and was typically higher in males and older age groups. In Brighton and Liverpool the estimated prevalence among men aged 15 to 44 was $2.8 \%$ and $2.5 \%$ respectively compared with $1.2 \%$ and $0.6 \%$ among women. Among men aged 30 to 44 the prevalence was estimated at $3.9 \%$ in Brighton and 3.6\% in Liverpool, compared with $1.4 \%$ among 
Table 2 Capture-repature estimates from covariate analyses for injectors age 15 to 44 years in Brighton, Liverpool, and 12 London Boroughs 2000/01

\begin{tabular}{|c|c|c|c|c|c|}
\hline Location, age, and sex & $\begin{array}{l}\text { Total } \\
\text { population }\end{array}$ & $\begin{array}{l}\text { Observed } \\
\text { IDU }\end{array}$ & $\begin{array}{l}\text { Estimate of } \\
\text { unobserved IDU }\end{array}$ & $\begin{array}{l}\text { Total estimate of } \\
\text { IDU }(95 \% \mathrm{Cl})\end{array}$ & $\begin{array}{l}\text { Estimated IDU prevalence } \\
(\%)(95 \% \mathrm{Cl})\end{array}$ \\
\hline \multicolumn{6}{|l|}{ Brighton* } \\
\hline Females $<30$ & 29042 & 106 & 172 & 278 (174 to 853 ) & $1.0(0.6$ to 2.9$)$ \\
\hline Females 30-44 & 29622 & 98 & 319 & 417 (144 to 2165 ) & $1.4(0.5$ to 7.3$)$ \\
\hline Females 15-44 & 58664 & 204 & 490 & 694 (369 to 2196 ) & $1.2(0.6$ to 3.7$)$ \\
\hline Males $<30$ & 27156 & 259 & 132 & 391 (326 to 528 ) & $1.4(1.2$ to 1.9$)$ \\
\hline Males 30-44 & 31212 & 393 & 826 & 1219 (773 to 2598$)$ & $3.9(2.5$ to 8.3$)$ \\
\hline Males 15-44 & 58368 & 652 & 957 & 1609 (1154 to 3109 ) & $2.8(2.0+5.3)$ \\
\hline Total & 117032 & 856 & 1448 & 2304 (1514 to 3737$)$ & 2.0 (1.3 to 3.2$)$ \\
\hline \multicolumn{6}{|l|}{ Liverpool* } \\
\hline Females $<30$ & 52391 & 122 & 170 & 292 (166 to 3242 ) & $0.6(0.3$ to 6.2$)$ \\
\hline Females 30-44 & 49450 & 174 & 148 & 322 (207 to 2814 ) & $0.7(0.4$ to 5.7$)$ \\
\hline Females 15-44 & 101841 & 296 & 318 & 614 (384 to 2904 ) & $0.6(0.4$ to 2.9$)$ \\
\hline Males $<30$ & 47544 & 306 & 350 & 656 (529 to 862$)$ & $1.4(1.1$ to 1.8$)$ \\
\hline Males 30-44 & 45746 & 620 & 1020 & 1640 (1401 to 2641$)$ & $3.6(3.1$ to 5.8$)$ \\
\hline Males 15-44 & 93290 & 926 & 1370 & 2296 (2019 to 3297$)$ & 2.5 (2.2 to 3.5$)$ \\
\hline Total & 195131 & 1222 & 1688 & 2910 (2546 to 4977$)$ & 1.5 (1.3 to 2.6$)$ \\
\hline \multicolumn{6}{|l|}{12 London boroughs* } \\
\hline Females $<30$ & 336000 & 438 & 1208 & 1646 (1060 to 3405$)$ & $0.5(0.3$ to 1.0$)$ \\
\hline Females 30-44 & 356991 & 563 & 2144 & 2707 (1696 to 12211$)$ & $0.8(0.5$ to 3.4$)$ \\
\hline Females 15-44 & 692991 & 1001 & 3352 & 4353 (3156 to 10658$)$ & $0.6(0.5$ to 1.5$)$ \\
\hline Males $<30$ & 317606 & 1255 & 3483 & 4738 (3641 to 6682) & $1.5(1.1$ to 2.1$)$ \\
\hline Males 30-44 & 350670 & 1979 & 5712 & 7691 (5901 to 10649) & $2.2(1.7$ to 3.0$)$ \\
\hline Males 15-44 & 668276 & 3234 & 9195 & 12429 (9994 to 15413$)$ & $1.9(1.5$ to 2.3$)$ \\
\hline Total & 1361267 & 4235 & 12547 & $16782(13793$ to 21621$)$ & $1.2(1.0$ to 1.6$)$ \\
\hline \multicolumn{6}{|l|}{ London estimates sub-divided $†$} \\
\hline Inner London & 884856 & 3697 & 10987 & 14684 (10744 to 29203$)$ & 1.7 (1.2 to 3.3$)$ \\
\hline Outer London & 476411 & 538 & 1561 & 2099 (1554 to 3743$)$ & $0.4(0.3$ to 0.8$)$ \\
\hline \multicolumn{6}{|c|}{$\begin{array}{l}{ }^{*} \text { Model interactions (data sources: } A=\text { treatment; } B=\text { syringe exchange; } C=\text { arrest referral; } D=\text { survey and } A \& E ; C D=C \text { and } D \text { combined) and goodness of fit }\left(G^{2}\right. \\
\text { degrees of freedom, } A I C) \text {. Brighton: interactions: } A^{*} B, A^{*} C, B^{*} D, C^{*} D ; G^{2} 11.81, p \text { value } 0.98 \text {, degrees of freedom } 24, A I C-36.19 . \text { Liverpool: males }- \\
\text { interactions: } A^{*} B, A^{*} C, B^{*} C ; G^{2} 13.97 \text {, p value } 0.45 \text {, degrees of freedom } 14, A I C-14.03 \text {. Liverpool: females }- \text { interactions: } A^{*} B^{*} D, A^{*} C^{*} D ; G^{2} 0.057, P \text { value } 1 \text {, } \\
\text { degrees of freedom } 6, A I C-11.94 \text {. London: interactions: } A^{*} B, A^{*} C ; G^{2} 5.66, p \text { value } 0.225 \text {, degrees of freedom } 4, A I C-2.34 \text {. †London boroughs: inner } \\
\text { London: Camden, Hammersmith and Fulham, Islington, Kensington and Chelsea, Lambeth, Lewisham, Southwark, Westminster; outer London: Brent, Ealing, } \\
\text { Harrow, Hounslow. }\end{array}$} \\
\hline
\end{tabular}

men aged 15-29 in both cities. Overall in the 12 London boroughs the estimated prevalence of IDU was $1.9 \%$ among men and $0.6 \%$ among women aged 15 to 44 .

Table 3 shows estimates of public health indicators associated with injecting drug use in Brighton, Liverpool, and London as a whole. The number of IDU that receive treatment annually in general practice or at a specialist drug agency was not readily available and drawn from a variety of sources. All provide convergent evidence that the proportion of IDUs receiving treatment is low: at $22 \%$ in Liverpool and London, and $16 \%$ in Brighton.
The best available data indicated that in London nearly five million syringes are distributed per annum, with over 400000 in Brighton, and 560000 in Liverpool. These equate to approximately the same proportionate coverage in Brighton and Liverpool at around 190 syringes per person per year (or one syringe every two days) and slightly less in London at around one syringe every 2.5 days. Given that IDUs inject on average twice a day, this would suggest that current levels of activity provide sterile equipment for approximately $27 \%$ of all injections by IDU in Brighton and Liverpool and $20 \%$ in London. ${ }^{35}$

Table 3 Public health indicators using the estimates for injectors age 15 to 44 years in Brighton, Liverpool, and London 2000/01

\begin{tabular}{|c|c|c|c|c|c|c|}
\hline \multirow[b]{3}{*}{ Public health indicator } & \multirow{2}{*}{\multicolumn{2}{|c|}{$\begin{array}{l}\text { Brighton } \\
\text { Estimate } 2304\end{array}$}} & \multirow{2}{*}{\multicolumn{2}{|c|}{$\begin{array}{l}\text { Liverpool } \\
\text { Estimate } 2910\end{array}$}} & \multirow{2}{*}{\multicolumn{2}{|c|}{$\begin{array}{l}\text { London* }^{*} \\
\text { Estimate } 34400\end{array}$}} \\
\hline & & & & & & \\
\hline & $\begin{array}{l}\text { Number of } \\
\text { events }\end{array}$ & Indicator & $\begin{array}{l}\text { Number of } \\
\text { events }\end{array}$ & Indicator & $\begin{array}{l}\text { Number of } \\
\text { events }\end{array}$ & Indicator \\
\hline $\begin{array}{l}\text { Proportion of injectors } \\
\text { receiving structured } \\
\text { treatment† }\end{array}$ & 363 & $16 \%$ & 654 & $22 \%$ & 7500 & $22 \%$ \\
\hline $\begin{array}{l}\text { Annual number of syringes } \\
\text { distributed per IDU per yeart } \\
\text { (coverage per injection) }\end{array}$ & 429000 & $\begin{array}{l}186 \\
(27 \%)\end{array}$ & 566500 & $\begin{array}{l}195 \\
(28 \%)\end{array}$ & 4910000 & $\begin{array}{l}143 \\
(20 \%)\end{array}$ \\
\hline $\begin{array}{l}\text { Opioid overdose mortality } \\
\text { rate§ }\end{array}$ & 48 & $2.1 \%$ & 28 & $0.96 \%$ & 236 & $0.7 \%$ \\
\hline
\end{tabular}

*Estimate of number of injectors based on applying prevalence estimates for inner and outer London from 12 London boroughs to all of greater London. †Brighton: number in specialist drug treatment and primary care Brighton Drug Commissioning (personal communication); London: number in specialist drug treatment based on number and proportion receiving substitute treatment reported to London's National Drug Treatment Monitoring System supplemented by an estimate of number in treatment in primary care ( $\mathrm{Dr}$ Chris Ford, personal communication); Liverpool: (local drug treatment monitoring system). ¥Brighton: Brighton Drug Commissioning (personal communication); London: 1997 Survey and local SEP data ${ }^{26}$; Liverpool: Local SEP surveillance (John Moores University).§From Office of National Statistics Drug Related Deaths Database. 
The estimated annual opioid mortality rate based on the number of opioid overdose deaths identified by Office of National Statistics as the numerator and the prevalence estimates as the denominator was $2.1 \%$ in Brighton compared with about $1.0 \%$ in Liverpool and $0.7 \%$ London.

\section{DISCUSSION}

These estimates indicate substantial numbers of injecting drug users in the three cities (Brighton, Liverpool, and London) and the subsequent measures of coverage serve to emphasise the need for further public health action to treat and prevent the harms associated with injecting drug use.

\section{Credibility of the estimates}

The findings suggest that between 1 in 50 and 1 in 80 of the adult population aged 15-44 in the three cities is an injecting drug user, which equates to between 10 and 18 patients in a typical general practice list of 2000 patients with 900 aged 15-44. Thus, in Brighton, Liverpool, and London the prevalence of injecting drug use among young adults is as common as diabetes and greater than many other chronic conditions such as epilepsy or psychosis. The prevalence also was higher among males and in the "older" age-group 30-44, which implies that a large proportion of the injecting population is an aging cohort.

Given abbreviated data on the subjects (initials rather than full name), there is potential for under-matching, which would lead to over-estimates of the population. ${ }^{17}$ Furthermore, the inadequacy of datasets in London to cover the whole of the geographical area and the information on area of residence limited analyses for inner and outer London and separate boroughs. However, these estimates are plausible. Firstly, there is a consistency in the size of the estimates, and distributions by age group and gender between the three cities. Secondly, the ratio between the unobserved and observed number of injectors were not excessive. Moreover, the number of truly hidden IDUs will be lower than the unobserved population. For instance in London, data were not collected from five local syringe exchange programmes (SEP) and three hospital A\&E departments or from any pharmacy offering syringe exchange, drug outreach team, or drop in service. Thirdly, a prevalence of over $1 \%$ has been recorded previously in Glasgow; and the higher prevalence in Brighton fits with evidence on overdose mortality. ${ }^{17}$ Finally, in Brighton and Liverpool where consultation has already taken place, local specialists and policy makers gave their support to the estimates.

\section{Coverage and public health implications}

The government aims to double the number of problem drug users in treatment. ${ }^{1}$ In the three sites there is ample opportunity for this, given that less than one in four IDUs are in receipt of treatment at any one time. Unfortunately data on the number in treatment were of poor quality and requires urgent improvement.

The estimated coverage of syringe distribution at approximately one clean syringe per injector every two to 2.5 days (or $20 \%$ to $27 \%$ of all injections) was similar in the three areas, adding support to the prevalence estimates. While policy makers in England deserve credit for reaching such a high coverage in comparison with many other cities and countries worldwide it should still be regarded as insufficient. Corroboration of the coverage in London especially is required. The prevalence of hepatitis $\mathrm{C}$ virus infection among IDUs in London, Liverpool, and Brighton is higher than many other areas in England and Wales ${ }^{36}$; and the sharing of injecting equipment continues at high levels. ${ }^{37}$ Syringe exchange distribution needs to be expanded, perhaps doubled, to reduce the opportunity for sharing and minimise the risk of viral transmission; especially hepatitis C infection.

Annually injecting drug users are estimated generally to have a risk of fatal overdose of nearly $1 \%$, as found for the estimates for London and Liverpool, which tends to increase with duration of injecting. ${ }^{38}{ }^{39}$ In Brighton, not only was the prevalence of injecting estimated to be higher than the other cities, but the proportion of opioid users reported as dying from overdose was also estimated to be higher at $2 \%$. It seems that Brighton may have proportionately more opioid overdose deaths than any other city in the UK. ${ }^{40}$ In 2000, Brighton recorded 0.4 opioid overdose deaths per 1000 adult population aged 15 to 44, compared with 0.1 in Liverpool and London, which cannot be explained entirely by differences in the size of the IDU population. Clearly, local policymakers should consider expanding the availability of substitution treatment, and continue investigating why the risk of fatal opioid overdose is so high in Brighton.

\section{Methods and future work}

Indirect methods of estimating prevalence are inherently uncertain, and the figures they produce need to be treated cautiously. There are no "simple rules" for determining reliability or the sample size required, ${ }^{41}$ though in general the larger the study the better the evidence. None the less, we show that by using a consistent approach and new statistical techniques (that have not been used before for drug use or multiple data sources), useful estimates describing the extent of drug use in the population can be obtained. Further work will be conducted on model selection and on exploring the limits of the number of covariates that can be included in capture-recapture analyses. Capture-recapture also has been suggested to provide the most accurate estimate of prevalence when compared with other epidemiological counting methods. ${ }^{42}$

During the study, substantial if not most effort and time was spent on gaining access and collecting routine data. It is vital that prevalence estimation-through capture-recapture-should be included as a key objective of current and future data sources, such as monitoring systems for drug treatment, and the national Arrest Referral scheme (as has been suggested for the surveillance of other chronic disease problems ${ }^{13}{ }^{43}$ ). Better evidence will be available therefore to support or to counter claims that insufficient numbers of injecting drug users are being treated, and to bring some rationality to debate on drug policy.

\section{ACKNOWLEDGEMENTS}

We thank the numerous individuals and services in Brighton, Liverpool, and London that allowed us to collect their data.

\section{Authors' affiliations \\ M Hickman, V Hope, Centre for Research on Drugs and Health} Behaviour, Social Science and Medicine, Primary Care and Population Sciences, Imperial College, London, UK

V Higgins, M Bellis, Centre for Public Health, Liverpool John Moores University, Liverpool, UK

K Tilling, Social Medicine, University of Bristol, Bristol, UK

A Walker, Brighton and Hove Drug Action Team, Brighton, UK

J Henry, Academic Department of Accident and Emergency Medicine, Imperial College, London, UK

Funding: the study was funded by the Home Office Research and Statistics Directorate. Matthew Hickman is funded through a Department of Health Public Health Career Scientist award. The Centre for Research on Drugs and Health Behaviour is core funded by the Department of Health.

Conflicts of interest: none declared. 


\section{REFERENCES}

1 Department of Health. Tackling drugs to build a better Britain. The government's 10-year strategy for tackling drug misuse. (Cm 3945). London: The Stationery Office, 1998.

2 United Nations. Declaration of Commitment on HIV/AIDS. United Nations General Assembly Special Session on HIV/AIDS. 25-27 Jun 2001.

3 Davies N. How Britain is losing the drugs war. Guardian 2003;22 May.

4 Manski C, Pepper J, Petrie C, eds. Informing America's policy on illegal drugs: What we don't know keeps hurting us. Washington, DC: National Academy Press, National Research Council, 2001:424.

5 Aust R, Sharp C, Goulden C. Prevalence of drug use: key findings from the 2001/2002 British Crime Survey. Findings 182. London: Home Office Research, Development and Statistics Directorate, 2002:6.

6 Department of Health. Statistics from the Regional Drug Misuse Databases on drug misusers in treatment in England, 2000/01. Department of Health Statistical Bulletin 2001:33.

7 Seber GAF. The estimation of animal abundance and related parameters. 2nd ed. London: Charles W Griffin, 1982.

8 Suzman S, Sirken MG, Cowan CD. Sampling rare and elusive populations. Science 1988;240:991-6.

9 Le Cren, ed. A note on the history of mark-recapture population estimates. Journal of Animal Ecology 1965;34:453-4.

10 Chandra Sekar C, Edwards Deming W. On a method of estimating birth and death rates and the extent of registration. Am Stat Assoc J 1949;44:101-15.

11 Fienberg SE. Bibliography on capture-recapture modelling with application to census undercount adjustment. Survey Methodology 1992;18:143-54.

12 Hook EB, Regal RR. Capture recapture methods in epidemiology: methods and limitations. Epidemiol Rev 1995;17:243-64.

13 LaPorte RE. Assessing the human condition: capture-recapture techniques. BMJ 1994;308:5-6.

14 International Working Group for Disease Monitoring and Forecasting Capture-recapture and multiple record systems estimation I: history and theoretical development. Am J Epidemiol 1995;142:1047-57.

15 Tocque K, Bellis MA, Beeching N, et al. Capture recapture as a method of determining the completeness of tuberculosis notifications. Comm Dis Public Health 2001;4:141-43.

16 Bishop YMM, Fienberg SE, Holland PW. Discrete multivariate analysis: theory and practice. Cambridge, MA: MIT Press, 1975.

17 Hickman M, Stimson G, Howe S, et al. Estimating the prevalence of problem drug use in inner-London: a discussion of three capture-recapture studies. Addiction 1999;94:1653-662

18 Frischer M, Leyland A, Cormack R, et al. Estimating the population prevalence of injection drug use and infection with human immunodeficiency virus among injection drug users in Glasgow, Scotland. Am J Epidemiol 1993;138:170-81.

19 Domingo Salvany A, Hartnoll RL, et al. Use of capture-recapture to estimate the prevalence of opiate addiction in Barcelona, Spain, 1989. Am J Epidemio 1995; 141:567-74.

20 Mastro TD, Kitayaporn D, Weniger BG, et al. Estimating the number of HIV infected injection drug users in Bangkok: a capture-recapture method. Am J Public Health 1994;84:1094-9.

21 Hser YI. Population estimates of intravenous drug users and HIV infection in Los Angeles County. Int J Addict 1993;28:695-709.

22 Larson A, Stevens A Wardlaw G. Indirect estimates of 'hidden' populations: capture-recapture methods to estimate the numbers of heroin users in the Australian Capital Territory. Soc Sci Med 1994;39:823-31.
23 Benyon C, Bellis MA, Millar T, et al. Hidden need for drug treatment services: measuring levels of problematic drug use in the North West of England. $\mathrm{J}$ Public Health Med 2001;23:286-91.

24 Tilling K, Sterne JAC. Capture recapture models including covariate effects. Am J Epidemiol 1999;149:392-400.

25 Tilling K, Sterne JAC, Wolfe CDA. Estimation of the incidence of stroke using a capture-recapture model including covariates. Int J Epidemiol 2001;30:1351-9

26 Oerton J, Hunter G, Hickman M, et al. Arrest referral in London police stations: characteristics of the first year. A key point of intervention for drug users? Drugs Education Prevention and Policy 2003;10:73-85.

27 Parsons J, Hickman $M$, Turnbull $P$, et al. Over a decade of syringe exchange: results from 1997 UK survey. Addiction 2002;7:845-50.

28 Baker A. ONS drug-related deaths database: first results for England and Wales, 1993-97. Health Statistics Quarterly 2000;5:57-60.

29 Hook EB, Regal RR. Validity of methods for model selection, weighting for model uncertainty, and small sample adjustment in capture-recapture estimation. Am J Epidemiol 1997; 145:1138-44.

30 Hook EB, Regal RR. Accuracy of alternative approaches to capture-recapture estimates of disease frequency: internal validity analysis of data from five sources. Am J Epidemiol 2000;152:771-9.

31 Sakamoto $Y$, Ishiguro M, Kitagawa G. Akaike information criterion statistics. Tokyo: KTK Scientific, 1986.

32 Draper D. Assessment and propogation of model uncertainty. J R Stat Soc [B], 1995;57:78-9

33 Evans MA, Bonett DG. Bias reduction for multiple-recapture estimators of closed population size. Biometrics 1994;50:388-95.

34 Buckland ST, Garthwaite PH. Quantifying precision of mark recapture estimates using the bootstrap and related methods. Biometrics 1991;47:255-68.

35 Hunter GM, Stimson GV, Judd A, et al. Measuring injecting risk behavior in the second decade of harm reduction: a survey of injecting drug users in England. Addiction 2000;90:1351-61.

36 Unlinked Anonymous Surveys Steering Group. Prevalence of HIV and hepatitis infections in the United Kingdom 2000. Annual report of the unlinked anonymous prevalence monitoring programme. London: Department of Health, Public Health Laboratory Service, Institute of Child Health, 2001.

37 Hope VD, Rogers PA, Jordan L, et al. Sustained increase in the sharing of needles and syringes among drug users in England and Wales. AIDS 2002;16:2494-6.

38 Hulse GK, English DR, Milne E, et al. The quantification of mortality resulting from the regular use of illicit opiates. Addiction 1999;94:221-9.

39 White JM, Irvine RJ. Mechanisms of fatal opioid overdose. Addiction 1999:94:961-72.

40 Bird SM, Hutchinson SJ, Goldberg DJ. Drug related deaths by region, sex, and age-group per 100 injecting drug users in Scotland, 2000-01. Lancet 2003;362:941-4.

41 Davies AG, Cormack RM, Richardson AM. Estimation of injecting drug users in the City of Edinburgh, Scotland, and number infected with human immunodeficiency virus. Int J Epidemiol 1999;28:117-21.

42 Lange J, LaPorte R, Talbott E, et al. Capture-recapture method: the gold standard for incidence and prevalence. N Z Med J 2003;116:1176.

43 Tilling K. Capture-recapture methods-useful or misleading? Int J Epidemiol 2000;30:12-14. 